\title{
El PCE y el feminismo en España (1960-1982)
}

\author{
M Teresa LÓPEZ HERnÁNDEZ \\ Centro de Estudios de la Mujer de la Univesidad de Salamanca \\ mtlopez@usal.es
}

Recibido: 15.12 .2011

Aceptado: 30.01.2012

\section{RESUMEN}

En los años 60 el comunismo consideró al feminismo como un competidor a la hora de incorporar mujeres al Partido.

El fin de la dictadura y la transición a la democracia hizo necesario la colaboración con los movimientos feministas en cuanto a incorporar al discurso comunista las demandas femeninas, pero también para no perder poder político ni afiliadas.

Sin embargo, es cierto que los medios de comunicación comunistas ayudaron a difundir las reivindicaciones femeninas.

Palabras clave: comunismo, feminismo, movimientos feministas, problemas específicos de las mujeres.

\section{Communism and feminism in Spain (1960-1982)}

\begin{abstract}
In the 1960s feminism was considered by communism as a competitor when it came to incorporating women to party politics.

The end of the Spanish dictatorship and the transition to democracy made it necessary for communists to collaborate with feminist movements by incorporating the specific problems of women into communist discourse; however it was also done in order to avoid losing political power and women's membership. Nonetheless, it is true that communist mass media helped to spread specific feminist demands.
\end{abstract}

Key words: communism, feminism, feminist movements, specific problems of women.

\section{INTRODUCCIÓN}

En 1960 no existía en España un movimiento feminista consolidado. La frustración de la experiencia republicana y el régimen político que se impuso después de la Guerra Civil lo impidieron. El único movimiento femenino permitido por el poder, la Sección Femenina, desde luego no era feminista. Por el contrario, el grueso de su mensaje y de su propaganda era esencialmente antiemancipatorio.

La reaparición del Movimiento Feminista vino estimulado por los cambios sociales y económicos habidos en España, el mayor contacto con el exterior y la entrada de ideas ya extendidas por otros países. Todos estos factores fomentaron su aparición, y contribuyeron a crear una conciencia de que era necesaria la batalla 
por unos derechos que no serían concedidos sin presión (Seminario de Estudios Sociológicos de la Mujer, 1986:29-40; Grau Biosca, 2000: 736-739).

Desde 1960 a mediados de los 70, surgen los primeros grupos y asociaciones con demandas de mejoras para las mujeres en los distintos ámbitos de la vida ${ }^{1}$. A partir de 1976 muchos de estos grupos siguieron su actividad, a ellos se unieron otras organizaciones que defendían intereses específicos de amplios colectivos, o aquellos que afectaban a una generalidad ${ }^{2}$ como era la consecución del cambio legislativo y aunaron sus esfuerzos para que el proceso se realizara (Salas y Comabella, 1999: 27-94).

Los grupos femeninos activos abarcaban todas las ideologías, desde los encuadrados dentro de movimientos católicos de antigua implantación como la Acción Católica, hasta los más autónomos, también católicos, de nuevo cuño como el SESM (Seminario de Estudios Sociológicos de la Mujer), y los grupos de izquierda, como el M.D.M. (Movimiento Democrático de Mujeres) plural, aunque mediatizado por el Partido Comunista (Di Febo, 1979; Moreno Sardá, 1977).

El SESM aparece en 1960 creado por María Campo Alange y, aunque fundado como mero grupo de estudio, participará en diversos congresos presentando en ellos sus propuestas. En 1959, todavía en proceso de constitución, participa en el I Congreso de la Familia, enfrentándose con Sección Femenina por su propuesta del "Sueldo del Ama de Casa".

También en 1970 participan en el I Congreso Internacional de la Mujer que organizó Sección Femenina con una ponencia sobre “Mujer y Educación”. Su ideología se enmarca en el catolicismo progresista y considera a las mujeres como un grupo social atrasado y discriminado en su integración en la sociedad cuya promoción se conseguirá por medio de la educación y la incorporación al mercado de trabajo; para su completa realización en la sociedad reivindicarán el derecho a la educación, al trabajo y a la igualdad jurídica (Grau Biosca, 2000:738).

El MDM, grupo de izquierdas, nace en 1965, promovido por el PC y el PSUC.

${ }^{1}$ Había grupos que defendían los intereses de las mujeres, pero no desde un punto de vista feminista, como la Asociación de Mujeres Empresarias Españolas (1971). En este mismo año surge la Asociación de Mujeres Juristas, fundada por María Telo, su influencia se dejo sentir en las reformas del Código Civil y algunos aspectos de la Legislación Laboral y Penal. Las asociaciones se multiplican en los años siguientes, la Asociación de Mujeres Separadas Legalmente, denunciaba la desigualdad ante la ley que sufrían las mujeres (1973). La única compuesta por hombres y mujeres fue APEC (Asociación para la Promoción y Evolución de la Cultura) que pretendía modificar el concepto de mujer dentro del terreno cultural (1973).

2 Colectivo Jurídico Feminista en 1975; Asociación Universitaria para el Estudio de los Problemas de la Mujer (AUPEPM), se crea como asociación en 1976; Madres Solteras para la Igualdad Jurídica de sus hijos en 1977; Asociación Castellana de Planificación Familiar en 1978. 


\section{EL MOVIMIENTO DEMOCRÁTICO DE LAS MUJERES}

Los partidos de izquierdas, entonces clandestinos, estaban interesados en la movilización de masas en la que se incluían a las mujeres, a las que intentarán convencer de que no deben limitarse a luchar por sus intereses específicos, sino ponerse al servicio de causas generales que a la postre revertirían en su propia emancipación (Moreno Sardá, 1988:103). Mundo Obrero presentó por entonces al Partido Comunista como defensor de las mujeres asegurando que entre las tradiciones "gloriosas" del Partido estaba la lucha por la conquista y el "respeto de los derechos de la mujer y de sus más sentidas aspiraciones" (Mundo Obrero, marzo 1965:2).

Este planteamiento se atenía a la doctrina marxista. Según Engels, en "El origen de la familia, la propiedad privada y el Estado", la primera opresión de clases es la del sexo femenino por el masculino, en medio de una sociedad dividida en clases. La solución, por tanto, era cambiar la sociedad hacia parámetros socialistas. Una vez derrotado el capitalismo, la discriminación femenina acabaría.

Por ello, la lucha de las mujeres entra dentro de reivindicaciones generales y es transitoria, desapareciendo cuando desaparezcan las circunstancias que producían la opresión y discriminación. Así se manifiesta en la publicación del M.D.M de Madrid, La Mujer y la Lucha:

"En esta situación de manifiesta inferioridad, es lógica y justa la unión, pues no pretende privilegios, sino igualdad, tal unión, MOVIMIENTO DEMOCRÁTICO DE MUJERES, nosotras la concebimos TRANSITORIA. Sin nace para defenderse de unas estructuras opresoras y discriminatorias, ha de desaparecer por tanto, cuando desaparezcan tales circunstancias, lo contrario nos parecería aberración.

Nuestros problemas se resolverán SOLO si van unidos al esfuerzo común de todo el pueblo, de los trabajadores y demás sectores en lucha, pero es claro, que nadie mejor que nosotras, por vivirlas, podemos denunciar y convertir en energía movilizadora nuestras propias discriminaciones” ( La Mujer y la Lucha, 1968).

Y se reiteraba seis años después en A Muller e a Loitia publicación del Movimiento Democrático de Mujeres de Galicia:

“...Como objetivo de las libertades democráticas, el Movimiento tienen planteada la lucha por la liberación de la mujer. Queda fuera de toda duda, que el Movimiento sabe que la liberación de la mujer sólo podrá darse plenamente cuando desaparezcan de la sociedad todas las situaciones de explotación, que nuestra liberación se realizará al mismo que la de todas las clases populares explotadas y oprimidas. Y esto sucederá cuando desterremos para siempre la explotación del hombre por el hombre con la instauración del Socialismo: Sólo en una sociedad libre puede haber mujeres libres” (A Muller e a Loitia, julio 1974: ${ }^{\circ}$ extraordinario). 
Pronto surgieron entre los comunistas voces que alertaron de que tenían que concebir de otro modo el papel que jugaban éstas dentro de la Organización. Así los expresaba un artículo publicado en Mundo Obrero en diciembre de 1969:

\begin{abstract}
"Ahora bien, atraer a esas mujeres, ganarlas para el Partido obliga a ponerse al día sobre algunas cuestiones. [...] Persiste la idea en algunos camaradas de que la militante sirve para tareas auxiliares pero no de dirección. [...] Algunas mujeres- sobre todo jóvenes- dejaron nuestras filas por todos esos frenos. [...] Eso de que "las mujeres están mejor entre ellas” no es cierto. La experiencia demuestra que trabajan y luchan mucho mejor junto a los hombres, sobre todo si éstos las consideran sin discriminación de ninguna clase. Así debe ser en el Partido Comunista” (N.P., 1969: 7).
\end{abstract}

La receta era pues la amalgama de hombres y mujeres y la aceptación de estas últimas en puestos directivos, que no puede calificarse de "feminista". Muchas de las mujeres que compartían las ideas políticas de izquierda y participaban en la lucha con los partidos que las sustentaban, no admitían tal calificativo y se cuestionaban si era o no correcto crear un grupo para defender sus intereses específicos ${ }^{3}$ (Grau Biosca, 2000: 738).

Fernanda Romeu Alfaro recuerda que, no obstante, a partir de 1968, las mujeres, afectadas por el paro, la carestía de la vida y la congelación salarial, propenderán a exigir la incorporación de sus propias reivindicaciones al discurso político, aprestándose el M.D.M. a combinar la lucha contra la Dictadura con las demandas femeninas específicas, no sin que tal decisión divida a veteranas y nuevas generaciones convivientes en la Organización. El número 2 del Boletín "Alborada” de dicho año sirvió a las estudiantes barcelonesas para el doble objetivo mencionado, y el 20 de abril de 1968, el M.D.M. catalán, de efímera vida, articuló un programa de reivindicaciones con motivo del llamamiento a las mujeres para que participasen en la manifestación de $1^{\circ}$ de Mayo (Romeu Alfaro, 1994: 94-109). Éstas aparecieron en adelante en el discurso y en los medios del Partido, lo que no impidió que las mujeres sirvieran a causas que no eran específicamente las de sus congéneres, como el apoyo a los presos políticos, la lucha por la amnistía o la confrontación con el Régimen y, en todo caso, el Partido Comunista que dominaba el M.D.M. y lo consideraba como un instrumento de control y proselitismo, se esforzó en todo momento en impedir que las movilizaciones de mujeres de desviaran hacia una acción exclusiva y en convencerlas de que, si olvidaban la lucha de clases como objetivo principal, jamás conseguirían su emancipación.

Con esta misiva, las mujeres comunistas serían invitadas a penetrar en todo tipo de plataformas, incluidas las formadas por mujeres, y a hegemonizarlas. En 1968 se integraron en la Asociación de Amas de Casa, pero habiendo sido expulsadas de

3 En las filas socialistas las mujeres eran contrarias a la existencia de una organización específica de mujeres porque consideraban que incrementaba la discriminación de un grupo ya bastante discriminado. 
ella por su activismo militante, fundaron la Asociación de Amas de Casa Castellanas. También aprovecharon las Asociaciones de Padres de Alumnos, los Comités de Barrios, etc.

Los contactos del M.D.M. con grupos más propiamente feministas reforzaron en éste la consciencia de que cualquiera que fuera su compromiso con la "causa general” no podría abandonarse las demandas dirigidas a incluir intereses femeninos específicos sin perder capacidad de afiliación.

El interés por los problemas de las mujeres y el movimiento feminista fue aumentando en el Partido Comunista a medida que se transcurren los años 70 y se van desarrollando los movimientos a favor de los derechos femeninos.

En 1970 Mundo Obrero elogiaba el desarrollo del Movimiento Democrático de Mujeres y denunciaba que el Congreso Internacional de la Mujer, que se había celebrado en Madrid, estuvo acaparado por las "reliquias de Sección Femenina” y fueron excluidas la mayoría de las mujeres. Se presentó un escrito con 1500 firmas para que constara dicha exclusión. Si bien el documento no se leyó a las congresistas, la prensa comunista se aseguró de que trascendiera. El PCE pensaba que: "el Congreso de la mujer no es tal si no defiende los intereses de todas las mujeres, trabajadoras, amas de casa, universitarias, jóvenes que no tienen escuelas de capacitación” (Mundo Obrero, 27 junio 1970: 5).

Pero ante la evidencia de que tanto el Partido Comunista como en CC.OO se reproducían los mismos esquemas que aparecían en la sociedad dando primacía al trabajo masculino y considerando el de la mujer como algo transitorio (Escario, Alberdi, López-Accotto, 1996: 259-260), se consideraban que era necesario conseguir el socialismo pero incorporando a un sector de la sociedad que se tenía abandonado:

"Todo se reduce a inducir a las obreras a una lucha apéndice de las reivindicaciones económicas y sindicales. [...] No sólo no hay reivindicaciones políticas en esa larga lista, sino que la explicación de tal planteamiento viene a ser: "vuestra lucha es la misma que la del proletariado. La mujer obrera tiene las mismas reivindicaciones del hombre. Luchad a su lado que cuando hayamos vencido, los camaradas os darán todo los que queráis”. ¿Pero cómo, si ni siquiera se sabe lo que hay que darle?”(Díaz, 1971:11).

Fue en la celebración del VIII Congreso del PCE, en 1972, cuando se vio la necesidad del ingreso de mujeres en sus filas y la formación de las que ya formaban parte de la organización para "enriquecer tanto el trabajo de masas como el específico del Partido". Se hacía pues imprescindible establecer las medidas necesarias que se desprendían de esa proclama (Sara, 1973). En los plenos y conferencias que celebran los militantes del Partido Comunista en la emigración se planteaban constantemente la incorporación de las mujeres a la militancia y la lucha. Son las participantes femeninas las que establecían qué se debería hacer en este sentido. 
Mundo Obrero propugnaba una acción dirigida a definir la concepción de la cuestión femenina, las perspectivas de liberación dentro del marco de la lucha por la democracia y el socialismo y el papel revolucionario que la mujer debe desempeñar en esa transformación de la sociedad (Mundo Obrero, 17 septiembre 1973).

Es en el suplemento dedicado a los emigrantes dentro del periódico citado donde más eco tienen las consignas sobre mujeres ante la clandestinidad que vivía el Partido Comunista en España. Se exponía la realidad de las trabajadoras emigrantes: desigualdad salarial con los trabajadores masculinos, deficiente formación profesional, ritmos de trabajo excesivos, etc. Como medio para subsanarlos se pedía la socialización de las tareas domésticas (guarderías, cantinas en fábricas y escuelas, servicios públicos baratos de limpieza, etc). También un seguro que cubriera todos los gastos ocasionados por la maternidad y permitiera a la parturienta un descanso de 14 semanas con indemnización diaria, todo ello unido a la maternidad libre y voluntaria, que pasaba por la "descriminalización del aborto”.

A la altura de 1973, el apoyo del PCE a las reivindicaciones de las mujeres iba más allá que la mera cuestión laboral, y debía llevar aparejado un cambio en la forma de plantearlo, formando "grupos de trabajo o Comisiones de Estudio para abordar el problema de la opresión de la mujer e imprimir un auténtico viraje de 180 grados en la cuestión femenina" (Mundo Obrero, 17 septiembre 1973).

Las que entendían esto mejor eran mujeres militantes que estimaban que el atraer a sus congéneres pasaba por definir los objetivos que ligaban la lucha de las mujeres a la lucha general del Partido Comunista, elaborando un programa destinado a movilizar nuevas fuerzas femeninas sin renunciar a su incardinación en el marco de la lucha de clases:
"Se ha puesto de relieve que la liberación de la mujer debe llevarse a cabo en el interior de la lucha de clases y no como un movimiento de emancipación de sí misma, pero no existe ninguna oposición entre cuestión femenina o lucha femeni- na y lucha de clases. La mujer debe luchar contra la opresión específica a través del planteamiento de sus reivindicaciones específicas, es decir, como mujer, den- tro de la lucha de clases” (Mundo Obrero, 17 septiembre 1973).

De este planteamiento ideológico se deducía lo que el Partido debía realizar: "un trabajo a la vez específico adaptado a todos los problemas femeninos actuales, y un trabajo general, o sea, adecuado para integrar a las mujeres en los objetivos generales del Partido" (Mundo Obrero, 17 septiembre 1973).

La praxis no siempre era coherente con esta teoría. Se abría algún espacio a la autocrítica al recoger la realizada por Sara Iribarren, militante comunista en Suiza, en su libro "La liberación de la mujer":

“... No basta con teorizar correctamente sobre la opresión de la mujer, reconocer las discriminaciones que sufre y defender la legitimidad del principio marxista de 
la lucha por corregirlas: hay que ir más lejos. Cuando se trata de pensar el problema a fondo, con todas sus consecuencias, y de adoptar una práctica, se produce una especie de evasión inconsciente que conduce, la mayoría de las veces, a no considerar el problema como prioritario, como urgente, a relegarlo para más tarde o dejar que las mujeres lo resuelvan por sí solas” (M.M., 1 julio 1973).

A partir de 1974 al M.D.M. se le añaden las siglas MLM (Movimiento de Liberación de la Mujer), pasando a denominarse MDM/MLM y evoluciona hacia prácticas más feministas (GIL RUÍZ, 1996: 153), aunque algunas autoras piensa que a pesar de esta orientación, siempre estuvieron limitadas por su supeditación a los intereses partidistas (Sánchez López, 1990: 89).

A pesar de que el PCE había reconocido la necesidad de que las mujeres se incorporaran a la lucha política y a la actividad partidista, seguía con una visión tradicional de las actuaciones en las que era más necesaria la participación de las mujeres. Con motivo de la Jornada Internacional de la Mujer celebrada en Bruselas en 1974, que congregó a mujeres de diversos países bajo el lema "Por el fin de las guerras coloniales, la liberación de los presos políticos y la lucha contra el fascismo”, el PCE decía que las mujeres emigradas debían actuar junto a los Consejos Consultivos de inmigrados y unirse en torno a cuestiones esenciales, como educación de los hijos, el problema de la vivienda, la lucha sindical... (Mundo Obrero, 10 abril 1974).

Era demasiado cara al Partido Comunista la doctrina de que solamente cuando se acabaran las situaciones de explotación, en una sociedad socialista, podría darse la liberación de las mujeres como para no darle especial énfasis.

No obstante parecer irrenunciable la apelación a la "causa general" comunista en el citado año, hubo intentos de buscar propuestas que pudieran captar más militancia femenina. Una vía podía ser denunciar la discriminación de las mujeres.

Cuando del 15 al 17 de noviembre de 1974 se celebra en Roma la Conferencia de los Partidos Comunistas de los países capitalistas de Europa sobre la condición femenina, Teresa Bonet, miembro del Comité Central del Partido, que había participado en ella, subrayaba en una entrevista la discriminación que sufrían las mujeres emigradas: trabajo, vivienda, vida familiar.

La declaración por parte de la ONU de 1975 como Año Internacional de la Mujer, debía dar paso a iniciativas y actividades para llegar a acuerdos del Partido Comunista con otros partidos, organizaciones femeninas y cristianas..., ya que la lucha por sus derechos agrupaba a mujeres de creencias y opiniones diversas.

Un participante en la Conferencia de Roma, Manuel Azcárate, reconocía que si bien la actuación del M.D.M. era positiva seguían existiendo "obstáculos y trabas reales en la comprensión de este problema en nuestras filas y el Partido debe ser 
también el partido de vanguardia en el problema femenino" (Mundo Obrero, 10 diciembre 1974).

A raíz de una reunión conjunta de Partido Comunista con un amplio número de cuadros femeninos de varios países de Europa, se hizo un balance de la incorporación de las mujeres y se concluyó que "Numerosas organizaciones del Partido ofrecen una imagen de Partido sólo para hombres. En el mejor de los casos, se piensa en las mujeres para tareas auxiliares” (Mundo Obrero, 7 enero 1975).

\section{EL AÑO INTERNACIONAL DE LA MUJER EN LA PRENSA COMUNISTA}

La Declaración del año Internacional de la Mujer no dejó de representar un desafío para el Partido Comunista.

A propuesta de la Federación Democrática Internacional de Mujeres, la ONU declara como tal 1975 (Comisión Nacional del Año Internacional de la Mujer, 1976), y ello sirvió para una toma de conciencia por parte de todos los grupos, cualquiera que fuera su ideología, de los problemas por resolver que afectaban al colectivo femenino.

El Régimen franquista respondió rápidamente encomendando a Sección Femenina coordinar las actividades de la conmemoración, representarlo en las que tuvieran dimensión internacional y controlar la información inherente.

El Partido Comunista reaccionó con indignación ante este intento de manipulación y monopolio de la causa de las mujeres (Segura, abril 1975), pero tampoco vio con satisfacción el desarrollo de numerosas actividades espontáneas de carácter feminista, que decidieron aprovechar el paraguas protector de la ONU para promover organizaciones y reivindicaciones de carácter autónomo.

El sindicato CC.OO experimentó parecido sobresalto al del partido que lo hegemonizaba: los lazos que habían ido tendiéndose hacia las trabajadoras, a las que se suponía capaces de entender el lenguaje de la lucha de clases, podían verse ahora debilitados por los cantos de sirena que llegaban del aparato Sindical y de Sección Femenina; que flexibilizaba posiciones y por la llamada del feminismo autónomo.

Sin embargo, la Gaceta de Derecho Social (GDS), revista de Comisiones Obreras, reseñará el desarrollo de las movilizaciones y actos que se realizaron con tal motivo. Publicó la primera información sobre el Año Internacional de la Mujer en 1974, envuelta en una extensa crónica sobre un informe elaborado por la O.I.T. Dicho informe se titulaba "Igualdad de oportunidades y de trato para las trabajadoras”, y sería sometido a la consideración de los países participantes en la 60 reunión de la Conferencia Internacional de Trabajo que se iba a celebrar en junio de 1975. 
En el documento- divulgado por la G.D.S. - se analizaban los obstáculos que impedían alcanzar la igualdad a las mujeres trabajadoras: consideración segregada de "trabajo de hombres" y "trabajo de mujeres", escasa preparación profesional de las féminas que se debe en muchos casos a la preferencia por dar estudios a los hijos varones, percepción de la presencia de trabajadoras en el mercado como una amenaza del terreno reservado a los hombres. Todos estos factores influyen en la desigualdad de remuneración por un trabajo igual.

En el mismo documento se subrayaba que los medios aplicados por los distintos países para superar esas dificultades chocaban con los hábitos del pasado, las limitaciones y barreras culturales y psicológicas, el tradicionalismo de la familia y de los sistemas educativos y de formación profesional (Alonso Ligero, 1978:101121).

La Gaceta recogía el llamamiento de la O.I.T. a los maridos para que compartieran las tareas domésticas con sus esposas, ya que las trabajadoras casadas soportaban una mayor carga de trabajo doméstico:

"Una distribución más equitativa de la carga que representa el trabajo doméstico y el cuidado de los niños entre el marido y la esposa constituye una de las soluciones posibles al problema. Esa distribución más justa es, además uno de los prerrequisitos esenciales para alcanzar la igualdad entre ambos sexos [...].hacer extensivo un justo trato a las trabajadoras constituye al mismo tiempo una importante etapa en el progreso de los derechos humanos y un medio de liberar un enorme potencial de producción” (Gaceta de Derecho Social, noviembre-diciembre 1974: 9).

Este texto, tan favorable a la igualdad de oportunidades, conviene subrayarlo por la novedad que suponía en España su asunción en un medio de comunicación de sustrato comunista. Recordaremos que una de las acusaciones lanzadas contra el Partido Comunista Español por la feminista Lidia Falcón, era precisamente que cuando exigía guarderías olvidaba en cambio proponer el reparto de las tareas domésticas de la pareja (Falcón, 2000:224).

En enero de 1975 otro artículo, se congratulaba de que se hubiera proclamado el Año Internacional de la Mujer, pero deslizaba contra su plasmación, calificada de discriminatoria, las consiguientes críticas al considerar que se estaba tratando en la mayoría de los casos los problemas de las mujeres de "clase alta", que en muchos casos se consideraban como "liberadas", mientras que las verdaderas protagonistas de los avances sociales conseguidos son las trabajadoras, esas que, según el informe de la O.I.T., disponen de menos de las dos terceras partes del tiempo libre que su marido4 (Alvarez Royo, enero 1975: 28).

\footnotetext{
4 Este artículo vuelve a contener el informe de la OIT ya recogido en el artículo sobre el mismo tema publicado en 1974 recordando que el número de trabajadoras en todo el mundo asciende a 562 millones.
} 
La información en Mundo Obrero sobre los actos del Año Internacional de la Mujer fue escasa. Se informó del Congreso Mundial de Mujeres que se celebró en Berlín del 20 al 24 de octubre, de las organizaciones que participarían, del número de representantes, las comisiones que se formarían, pero la noticia proporcionada no era exhaustiva (Mundo Obrero: octubre 1975: VII).

Sin embargo, el Partido Comunista parecía deseoso de recuperar posiciones ante las mujeres, que viraban cada vez más hacia la acción autónoma. Reconoció, aunque de forma discreta, que debía hacer autocrítica y dar un giro de 180 grados, al mismo tiempo que se proclamó enfáticamente "el Partido de la liberación de la Mujer”. En la II Conferencia del Partido Comunista se aprobó el manifiesto "Por la Liberación de la Mujer” como documento de discusión con vistas a la Conferencia del Partido sobre la cuestión femenina que se celebraría posteriormente (Mundo Obrero, septiembre 1975:8; M. S., octubre 1975:VI):
"somos conscientes de que, en nuestras propias filas, la discriminación de la mujer es una realidad; y de que aún muchos comunistas tienen ideas reaccionarias sobre el problema femenino. Superar esta situación exige, primero, reconocerla. Además comprender que hace falta una verdadera revolución en las mentalidades en esta materia” (M. S., octubre 1975: VI-VII).

Aunque el Partido Comunista no dejaba de insistir en que las condiciones propicias para acabar con las estructuras que determinaban la discriminación de las mujeres vendrían con el fin de la Dictadura y la instauración del socialismo, consideraba que podía compatibilizarse con la propuesta de combatir en todas aquellas áreas en las que las mujeres estaban discriminadas: legislación, educación, trabajo, familia, y lograr que ocuparan puestos dirigentes en el movimiento obrero (MUNDO OBRERO, septiembre 1975:2; octubre 1975:VII). No obstante estas proclamas, la cuestión se relegaba precisamente porque se consideraba que se resolvería automáticamente con la revolución socialista, y en consecuencia las tareas prioritarias son otras escamoteándose inconscientemente el problema específico que planteaba la militancia de las mujeres (Irribaren, 1975: VII).

La entidad del Movimiento Feminista era un hecho a la altura de 1975 cuando cuajó en una Plataforma de Organización y Grupos de Mujeres, con un programa pactado de reivindicaciones específicas, constituyendo un desafío a la voluntad de control del Partido Comunista ${ }^{5}$ (Fagoaga, 1991:650; Gil Ruiz, 1996: 152-153).

Cuando apenas pasados doce días de la muerte de Franco, se celebraron, aún en la semiclandestinidad, las Jornadas de Liberación de la Mujer, las mujeres comunistas

\footnotetext{
5 Ya en la democracia, el Partido Comunista decidió no secundar la labor del M.D.M., por considerar la Dirección Nacional del PCE que el M.D.M. había jugado un papel importante contra la dictadura, pero en los albores de la democracia había perdido su razón de ser, olvidando así toda la colaboración que este movimiento había prestado a la lucha antifranquista.
} 
del M.D.M. que las organizaron, coparon su dirección y desarrollo. No pudieron impedir sin embargo la presencia de otras mujeres con distintos planteamientos.

Hubo en aquellas Jornadas, multitudinarias y bulliciosas, feministas católicas, marxistas de obediencia partidista y feministas partidarias de acción autónoma 6 . No faltaron las feministas socialistas que reconocían la conveniencia de organizaciones específicamente dirigidas a luchar por reivindicaciones particulares sin renunciar a militar en las de su propia ideología. No se logró evitar el enfrentamiento entre las partidarias de la doble militancia y las que no admitían más causa emancipadora que la propia de las mujeres. Relata Lidia Falcón, que cuando la entonces dirigente del Movimiento Comunista Jimena Alonso se negó a facilitarle el micrófono, ello provocó el abandono de la sala por 110 mujeres y la emisión de un comunicado con unas conclusiones alternativas a las elaboradas por el Congreso dominado a su parecer por las comunistas, además de una pública denuncia de las manipulaciones del M.D.M. (Falcón, 2000:215) que acabaría por dañar la capacidad de reclutamiento del Partido Comunista y su control del Movimiento Feminista, que en adelante siguió su propio curso.

De la contrariedad que esta primera confrontación con el feminismo "radical" causó al Partido Comunista da cuenta el silencio de Mundo Obrero sobre las Jornadas de Liberación (Falcón, 2000:222-223), no obstante haber sido mujeres del PCE quienes las habían puesto en marcha. Por eso llama la atención que se hiciera eco de las mismas la Gaceta de Derecho Social. Eludió sin embargo esta publicación la confrontación habida en su seno, e informó de sus conclusiones de tal modo que el lector no avisado no había de enterarse de aquella batalla campal:

"la mujer asume la responsabilidad de definirse políticamente, y la de participar, junto al hombre, en la tarea de configurar el cambio democrático que este país está pidiendo a gritos [...] la mujer debe luchar para conseguir las libertades mínimas que se dan en todo país democrático, tales como el derecho de reunión y asociación.

Se afirma la necesidad de crear un movimiento feminista y autónomo que luche por sus derechos, en todos los planos de la vida de la sociedad. Sólo así, continúa diciendo el Congreso, se conseguirá que no se produzcan discriminaciones laborales, legales o familiares".

Aún recogiéndolo tan mal, con la apelación a un movimiento "feminista" incluido, era, en un medio comunista, una concesión?

\footnotetext{
6 Entre otras la Gaceta de Derecho Social destacaba la participación de aquellas organizaciones bien comunistas, bien próximas o dispuestas a la colaboración con el P.C.E, a saber: Asociación de Amas de Casa Castellana. HOAC. Diocesanas. Asociación de Mujeres Universitarias de Madrid y Barcelona. Comisión Femenina Amigos de la UNESCO de Alicante. Enlaces femeninos Sindicales de Madrid.

7 El feminismo no fue aceptado por el Partido como instrumento para la lucha de las mujeres hasta 1978. Sin embargo, la Gaceta de Derecho Social reconocía, en este editorial, la importancia de que "por primera vez en 39 años se celebrara un CONGRESO FEMINISTA abiertamente democrático en el que se toman posturas auténticamente críticas e independientes”.
} 
Pero el editorial terminaba por precisar sobre ese "movimiento feminista autónomo" algo que devolvería las aguas al molino del discurso comunista ortodoxo, a la "causa colectiva": "Nuestra lucha de mujeres, no es una lucha contra el sexo masculino, sino contra aquellas estructuras sociopolíticas que hacen posible que el hombre nos oprima” (Gaceta de Derecho Social, diciembre 1975:31).

Se añadía el comunicado leído por una trabajadora madrileña, en estas mismas Jornadas, en que pedía al movimiento obrero que no olvidara integrar las reivindicaciones de las trabajadoras, ya que ellas estaban dispuestas a prestar su contribución a la emancipadora lucha de clases ${ }^{8}$.

\section{EL “PARTIDO DE LIBERACIÓN DE LA MUJER”}

La definición del Partido Comunista como Partido de Liberación de la Mujer planteaba algunos dilemas: “¿Cómo hacer para llevar estas posiciones audaces a la práctica para que no se queden en declaraciones de principios?, ¿Qué camino seguir para colmar el enorme abismo existente entre ellas y la realidad?”. De nuevo se insistió en la necesaria renovación de la mentalidad que permitiera evitar la desproporción entre el número de militantes femeninas y el porcentaje que ocupaban puestos de responsabilidad o pertenecían a los Comités para que "las mujeres no sólo estén destinadas a ayudar en trabajos prácticos”, priorizando los aspectos organizativos sobre los programáticos.

Como consecuencia de la II Conferencia Nacional del PCE, en 1975, se celebra la Primera Conferencia sobre la Mujer en 1976. En ella ya se vio la necesidad de fomentar el Movimiento Feminista y colaborar con él. Había que "impulsar a las mujeres y su lucha dentro del Partido, incorporar la actividad y la lucha política a miles de mujeres”. Para ello se consideró imprescindible:

"la existencia de un amplio movimiento feminista, de carácter pluralista, que sepa combinar las reivindicaciones sociales más sentidas por las mujeres con la lucha contra todas las discriminaciones jurídicas, económicas, culturales y sexuales que sufre la mujer en España”.

Se discutió también la conveniencia de tener organizaciones mixtas u organizaciones específicas para las mujeres comunistas. La preocupación por incorporar mujeres y el interés de que colectivos femeninos realizaran un trabajo específico, llevó a decidir que: "con mayor flexibilidad es conveniente disponer de "un frente

8 En este documento denominado significativamente "COMUNICADO DE CLASE" se advierte el intento de contrarrestar la orientación del movimiento de mujeres hacia una autonomía creciente organizando a las trabajadoras del Metal, Administración, Textil, Artes Gráficas, Químicas, Sanidad, a fin de que no olvidaran que su objetivo prioritario debía ser la lucha de clases. 
de lucha" dedicado a este trabajo, con organizaciones y agentes adecuados" (Cinca, junio 1976:7; Montoliu, junio 1976:7 y julio 1976:12).

En las conclusiones sobre las Primeras Jornadas de la Mujer Trabajadora, en 1977, recogidas por Mundo Obrero, se seguía reflejando esta preocupación al afirmar que solamente si se convierte la "cuestión femenina" en una "cuestión masculina", y esto supone un cambio profundo en la mentalidad de los hombres y se incorpora a la práctica diaria, el Partido Comunista podría ser de verdad el "Partido de Liberación de la Mujer” (Duero, 16 febrero1977:10).

La prensa comunista acabaría por hacerse eco de la idea de que las mentalidades son difíciles de cambiar y la llegada del socialismo aunque crease las condiciones para la emancipación femenina podría no resolver todos los problemas, por ello había que crear las condiciones adecuadas para que las mujeres pudieran asumir las responsabilidades que les corresponden, y "el movimiento obrero debería abarcar la cuestión femenina en su totalidad, no viéndola solamente desde las relaciones de producción sino desde las relaciones hombre y mujer". Era fundamental unificar las dos perspectivas porque igual de erróneo era verlo sólo desde la perspectiva feminista, que verlo sólo desde el punto de vista económico sin vincularlo con la ideología (M.S., octubre 1975:VII; Irribarren, 10noviembre 1975:VI) .

Si el fin de la dictadura abría el panorama político a cambios imprescindibles en la legislación y en todos aquellos campos en los que no se reconocía la igualdad, también era cierto que comenzaba una batalla electoral, en la que había que evitar que los temas relativos a la mujer tuvieran poco alcance (Escario, Alberdi y LópezAccotto, 1996:266-267 y 322-323).

En este contexto, se veía a las mujeres que habían participado con éxito en la lucha antifranquista como una parte importante para consolidar los partidos y darles una mayor fuerza al incrementar el número de militantes, por su parte, las mujeres sabían que sus demandas no prosperarían sin unos derechos democráticos elementales que las sustentasen (Scalon, 1990:96).

Ante la fuerza alcanzada por el Movimiento Feminista, se planteó su participación en el ámbito político. En las Jornades Catalanes de la Dona, que se celebraron en Barcelona en mayo de 1976, uno de los debates más intensos fue éste y quedó claro que las mujeres querían hacer su propio movimiento aunque sin desligarlo de la lucha política, sino vinculado a ella (Putxet, junio 1976: 6).

A finales de los 70 fue un hecho el reconocimiento de las mujeres en un movimiento propio que las situaba unas veces al margen de toda organización mixta, y otras veces defendiendo el feminismo en sus organizaciones políticas, creyendo firmemente que no podían proyectar sus aspiraciones en la sociedad sólo a través de la relación entre mujeres (Grau Biosca, 2000: 742). 
Entre otros partidos políticos, el Comunista, viendo esas dudas y contradicciones, comenzó a interesarse por todos aquellos actos reivindicativos de la emancipación femenina celebrados a lo largo del período estudiado. Publicarlos indicaba dicho interés.

Mundo Obrero, en un artículo en el que recoge las conclusiones de la Conferencia Nacional del Partido sobre la problemática de la mujer, celebrada en Madrid en diciembre de 1978, subrayaba las posiciones del Partido Comunista respecto a las relaciones con las feministas:

"El PCE multiplicará sus esfuerzos para impedir la manipulación de las mujeres, bien sea desde los partidos conservadores, los sectores reaccionarios de la Iglesia, los departamentos de publicidad y venta de las grandes compañías, o los medios de comunicación a su servicio. Simultáneamente, el PCE multiplicará también sus iniciativas para establecer una relación directa con las masas femeninas, conocer mejor sus problemas, elaborar alternativas concretas para ellos y defenderlas con energía en la calle y en el Parlamento”.

Aún señalando siempre las limitaciones del Movimiento Feminista y su potencial confrontación con otras fuerzas progresistas, recordaba que el Partido Comunista no quería olvidar su "importancia actual y su potencialidad futura", por eso reconocía:

“...La necesidad de que el Partido siga con atención las distintas manifestaciones de la lucha de la mujer, estudie las formas que adopta en cada caso, y desarrolle más profundamente en su seno los ideales de emancipación y liberación de la mujer, traduciendo cotidianamente esto en la actividad política y en vida interna”.

Para lograr este objetivo se facilitaría la incorporación de militantes comunistas y militantes feministas, pero sin intentar integrar al Movimiento Feminista dentro de él:

“Todas las organizaciones del Partido deben promover expresamente la participación de una parte de sus militantes mujeres en este movimiento, así como procurar y facilitar la incorporación al Partido, de militantes feministas. En todo caso, la actividad de las mujeres comunistas en el movimiento feminista, partirá de la base de defender la independencia de este movimiento y procurar que se estructure y funcione de forma plenamente democrática y se orientará a lograr su desarrollo de masas y su confluencia, a partir de la lucha por la reivindicaciones específicas de la mujer, con las fuerzas del trabajo y la cultura, que actúan para consolidar la democracia y crear una sociedad socialista" (Mundo Obrero, 21-27 diciembre 1978:20).

El Día Internacional de la Mujer Trabajadora, en 1979, en un "clima de ebullición de reivindicaciones obreras”, Begoña San José hace desde la Gaceta Sindical (la GDS después de una reestructuración en 1980 paso a llamarse Gaceta Sindical) un llamamiento a la unidad entre movimiento obrero y movimiento feminista, que 
potencie la fuerza a la hora de combatir las contradicciones del capitalismo (San José, Marzo 1979:15).

Muchas militantes comunistas no veían ningún problema en la colaboración del Partido y el Movimiento Feminista, ni en pertenecer a los dos a la vez sin sentirse manipuladas. Dolores Calvet, miembro del PSUC, en una entrevista con motivo de las Jornadas Feministas celebradas en Granada, así lo ponía de manifiesto:

"Las mujeres del PSUC y del PCE realmente son capaces de mantener la autonomía del movimiento. Es una manera de enseñar a muchas mujeres que se puede militar en un partido o un sindicato, al mismo tiempo que en el movimiento feminista, y no por esto manipula nadie” (Gónzalez, 20-26 diciembre 1979:20-22).

La militancia en partidos políticos o movimiento feminista o en los dos a la vez fue una disyuntiva a la que se enfrentaron muchas mujeres. Cuando el movimiento feminista pasó a ser menos reivindicativo y entró en crisis se consideró si esta dualidad era la culpable de ello.

La prensa comunista aireó intencionadamente el silencio reivindicativo del Movimiento Feminista respecto a la aprobación y modificación de las leyes, sobre todo las que más afectaban a las mujeres, y señaló que aunque la legislatura era una actividad que correspondía más a los partidos y al Parlamento, parecía que "no existiera una presión popular a cargo de los movimientos feministas en apoyo de determinados proyectos".

Mientras en los partidos de izquierda y sindicatos se dedicaba una atención especializada a la mujer, las organizaciones feministas se iban disolviendo "tras ese estado de opinión que arrolladoramente han logrado crear en todo el país". Desde las organizaciones feministas eran conscientes del fallo que se había producido: "lo que ha fallado es el sistema organizativo del movimiento" (Otero, 22-28 mayo 1980:20-21).

A juicio de Begoña San José la amplia movilización social de 1976, la campaña electoral de 1977 y el proceso constitucional, estuvieron íntimamente relacionados con el Movimiento Feminista que tenía una relación crítica pero integrada con los partidos políticos democráticos. Fue a partir de la aprobación de la Constitución y la institucionalización de la política de izquierdas cuando se hizo más profundo el distanciamiento (San José, 1998:109). Porque lo partidos de izquierda apoyaron las ideas y reivindicaciones feministas, pero seguían predominando los "fines políticos globales prioritarios" en los que se reproducía la discriminación existente en la sociedad: "Y las mujeres "normales" se acabaron hartando, todas aquellas discusiones sobre la doble militancia, sobre la Constitución, era demasiado" (Escario, Alberdi y López-Accotto, 1996:250). 
Según G. Scanlon, la cuestión de prioridades (lucha feminista o lucha política) y de estrategia, unido al desencanto, la situación de crisis económica y la disminución de la militancia política, fueron las razones que socavaron la precaria unidad del movimiento feminista (Scalon, 1990:97).

El proceso en España era inverso al que se producía en Italia, mientras en España se daba un distanciamiento de las organizaciones feministas respecto a los partidos e instituciones, en Italia se estaba volviendo, desde hacia tres años, a una aproximación y un aumento de la cooperación (Mundo Obrero, 29 agosto-4 septiembre 1980: 20-21).

Es ese proceso el que trata de contrarrestar el Partido Comunista. En los encuentros sobre Feminismo y Política organizados por la Comisión por la Liberación de la Mujer del Comité Central del PCE y la Fundación de Investigaciones Marxistas, celebrados el 28 y 29 de marzo de 1981 en Madrid, se ratificaba la estrategia que articularía junto a la clase obrera a otros sujetos sociales: "al igual que el potencial revolucionario que supone el movimiento feminista y sus aportaciones teóricas al movimiento obrero, así cómo la necesidad de su autonomía y la doble militancia de las comunistas” (P.P.F y A.G., 3-9 abril 1981:11).

Había que evitar la dispersión de fuerzas en la lucha política y social. Esta preocupación se manifiesta en el X Congreso del Partido Comunista9 ${ }^{9}$, (González Hernández, 1989:571), donde la Comisión por la Liberación de la Mujer del Comité Central del PCE, hablaba sobre el feminismo y su relación con los partidos políticos. Había que encontrar formas de relación y colaboración con otros movimientos sociales para lograr unos objetivos comunes, pero desde la independencia de cada uno y apoyando la actitud crítica:

"En este plano, el movimiento feminista, requiere atención preferente de los comunistas, ya que enriquece el concepto tradicional del política al introducir la esfera de los personal y cotidiano en la lucha política [...] El movimiento feminista es autónomo en razón de la especificidad de su lucha; su autonomía e independencia respecto a partidos y organizaciones de masas no puede entenderse como separación de la lucha de fuerzas sociales de progreso” (Comisión por la Liberación de la Mujer, 3-9 julio 1981: 36).

9 El X Congreso del PCE se celebró en julio de 1981, estuvo caracterizado por el enfrentamiento entre el sector renovador y el oficial. Las propuestas de los renovadores eran: revitalizar el Partido en base a incrementar la democracia interna, reconocimiento de las corrientes internas y dar mayor flexibilidad a la acción política de los militantes permitiendo la existencia de tipos de militancia con distintos grados de vinculación, estas propuestas no prosperaron y se reforzó la posición "central” del Secretariado frente a los renovadores. 


\section{CONCLUSIONES}

Es innegable que los órganos de prensa comunista contribuyeron a difundir las actividades de las distintas asociaciones de mujeres y apoyaron sus reivindicaciones, y en este sentido, podemos afirmar que coadyuvaron al reconocimiento y la plasmación legislativa de los derechos de la mujer.

Según la opinión de las militantes comunistas, los esfuerzos en la captación de mujeres, plasmados en la conminación que en 1972, durante el VIII Congreso del PCE, hizo Santiago Carrillo a los comunistas de abandonar sus actitudes excluyentes con respecto a las mujeres y a ocuparse de la "cuestión femenina", obedecieron más a la necesidad de apoyo en la lucha contra la Dictadura y el recelo hacia los movimientos feministas como competidores potenciales, que a un verdadero interés por la causa femenina.

Sin embargo, el auge de los movimientos reivindicativos de mujeres y los cambios a todos los niveles que trajo consigo el fin de la dictadura hacia necesario aunar fuerzas para no dispersarse en la lucha contra el capitalismo. Al mismo tiempo, la legalización de los partidos políticos desencadenó el interés por la participación en las elecciones y en el sistema parlamentario e incrementó el deseo del Partido Comunista de atraer a las mujeres a sus filas, siendo flexibles en cuanto a la colaboración con el movimiento feminista y la pertenencia de las mujeres a dicho movimiento, al Partido o a los dos a la vez, sin menoscabo de la reivindicación de sus intereses específicos.

La renovación legislativa que reconocía derechos largos años demandados por las mujeres, unida a la convocatoria de varios procesos electorales durante el período estudiado, obligó a los partidos políticos a tener en cuenta los temas debatidos en la elaboración de sus programas y adaptar sus contenidos a aquellos que tenían gran repercusión social, aún considerando prioritarios los de índole política.

En el caso del Partido Comunista a ello se le añadieron los grandes conflictos internos por los que pasó que desembocarían en el X Congreso, en el cual la necesidad de reformas lo condujo a replantearse el papel jugado por las mujeres y su representación en las organizaciones políticas y en los cargos del partido.

Se puede concluir que, por razones de tipo clientelar y de atención a las propias directrices "políticas" del PCE, los comunistas asumieron las peticiones que en aquellos momentos las mujeres consideraban irrenunciables. Aunque hay que tener en cuenta el período estudiado, tan amplio en actividades políticas e institucionales, en el que primaron más la consideración y fortalecimiento de un partido, de un sindicato y la aprobación de unas leyes que se anunciaba que traerían consigo y facilitarían los derechos femeninos. 


\section{BIBLIOGRAFÍA}

A MULLER E A LOITIA (julio 1974), $n^{0}$ extraordinario. Publicación del M.D.M. de Galicia.

ALONSO LIGERO, $\mathrm{M}^{\mathrm{a}}$ de los Santos (1978): Directrices y normas internacionales sobre el trabajo de la mujer con responsabilidades familiares. En, El Trabajo de la mujer con responsabilidades profesionales, pp. 101-121. Madrid: Ministerio de Trabajo.

ALVAREZ ROYO (enero 1975): 562 millones de mujeres trabajadoras. Gaceta de Derecho Social, 44, p. 28.

Año Internacional de la Mujer. La trabajadora protagonista (noviembre-diciembre 1974). Gaceta de Derecho Social, $\mathrm{n}^{\circ}$ 42-43, p. 9.

CINCA, Alba (16 junio 1976): Avances del movimiento feminista. Hacia un frente Unitario. Mundo Obrero, $\mathrm{n}^{\circ} 24$, p. 7

COMISIÓN NACIONAL DEL AÑO INTERNACIONAL DE LA MUJER (1976): Situación de la mujer en España. Año Internacional de la Mujer y Año Internacional de la Mujer: Memoria. Madrid.

COMISIÓN POR LA LIBERACIÓN DE LA MUJER DEL COMITÉ CENTRAL DEL PCE (3-9 julio 1981): Tribuna del X Congreso. El movimiento feminista. Mundo Obrero, $\mathrm{n}^{\circ} 132$, p. 36.

Conferencia del Partido sobre la problemática de la mujer. Defender la independencia de los movimientos feministas (21-27 diciembre 1978). Mundo Obrero, ${ }^{\circ} 3$, p. 20.

II Conferencia del PCE ( $2^{\mathrm{a}}$ semana septiembre 1975). Mundo Obrero, $\mathrm{n}^{\circ} 27$, p. 8.

II Conferencia del PCE” ( $3^{\mathrm{a}}$ semana septiembre 1975). Mundo Obrero, n ${ }^{\circ}$ 28, p. 2.

Congreso Mundial de Mujeres ( $3^{a}$ semana octubre 1975). Mundo Obrero, $n^{\circ}$ 32, p. VII (suplemento emigración).

DI FEBO, Juliana (1979): Resistencia y movimiento de mujeres en España, 1936-1976. Barcelona: Icaria.

DIAZ, Carlota ( $1^{\mathrm{a}}$ quincena de marzo de 1971): ¿Por qué nos da miedo hablar de la liberación de la mujer?, Mundo Obrero, p. 11.

DUERO, Alberto (16 febrero 1977): Primeras Jornadas de la mujer trabajadora. Mundo Obrero, $n^{\circ}$ 7, p. 10.

En torno al problema femenino (17 septiembre 1973). Mundo Obrero, $\mathrm{n}^{\circ} 16$, p. s/n (suplemento emigración).

ESCARIO, Pilar, ALBERDI, Inés y LÓPEZ-ACCOTTO, Ana Inés (1996): Lo personal es político. El Movimiento Feminista en la Transición. Madrid: Instituto de la Mujer.

FAGOAGA, Concha (1991): La democracia. En Anderson, B. y Zinsser, J., Historia de las Mujeres: una historia propia, vol. II, pp. 617-634 . Barcelona: Crítica.

FALCÓN, Lidia (2000): Mujer y poder político. Madrid: Kira Edit.

GIL RUIZ, Juana $\mathrm{M}^{\mathrm{a}}$. (1996): Las políticas de igualdad en España: Avances y retrocesos, Granada: Universidad de Granada.

GONZÁLEZ, Anabel (20-26 diciembre 1979): Jornadas feministas. No hubo aportaciones nuevas. Mundo Obrero, n ${ }^{\circ}$ 54, pp. 20-22.

GONZÁLEZ HERNÁNDEZ, Juan Carlos (1989): El Partido Comunista de España en el proceso de transición política. En, Tezanos, J.F., Cotarelo, R. y Blas, A., eds., La transición democrática española, pp., 543-585. Madrid: Sistema. 
GRAU BIOSCA, Elena (2000): De la emancipación a la liberación y valoración de la diferencia. El movimiento de mujeres en el estado Español, 1965-1990. En, Duby, G. y Perrot, M., dirs., Historia de las Mujeres, pp. 736-748. Madrid: Santillana.

IRIBARREN, Sara (10 noviembre 1975): Acerca de la militancia femenina. Mundo Obrero, n ${ }^{\circ} 36$, p. VII (suplemento emigración).

Jornada Internacional de la Mujer (10 abril 1974). Mundo Obrero, $n^{\circ}$ 7, p. s/n (suplemento emigración).

La lucha de las mujeres por sus reivindicaciones económicas y derechos políticos (marzo 1965). Mundo Obrero, p. 2.

LA MUJER Y LA LUCHA (1968). Publicación del M.D.M. de Madrid.

La mujer y el Partido (7 enero 1975). Mundo Obrero, $\mathrm{n}^{\circ}$ 1, p. s/n (suplemento emigración).

La mujer, un factor que cambia Italia (29 agosto-4 septiembre 1980). Mundo Obrero, $n^{\circ}$ 90, pp. 20-21.

Las no invitadas al Congreso de la Mujer (27 junio 1970). Mundo Obrero, $\mathrm{n}^{\circ} 12$, p. 5.

Los comunistas y la condición femenina. Conferencia de los PP.CC. de Europa Occidental (10 diciembre 1974). Mundo Obrero, $\mathrm{n}^{\circ} 22$, p. 6.

Llamamiento del PCE. Por la Liberación de la Mujer (1 $1^{\mathrm{a}}$ semana octubre 1975). Mundo Obrero, ${ }^{0}$ 30, p. VII (suplemento emigración).

M. M. (1 julio 1973): La liberación de la Mujer. Mundo Obrero, nº 14, p. s/n (suplemento emigración).

M. S. (1 ${ }^{\text {a }}$ semana octubre 1975): El Partido después de la II Conferencia y El Manifiesto del Partido por la Liberación de la Mujer. Mundo Obrero, $n^{\circ}$ 30, p. VIVII (suplemento emigración).

M. S. ( $3^{\mathrm{a}}$ semana octubre 1975): El Manifiesto del Partido por la Liberación de la Mujer. Mundo Obrero, no 32 , p VII (suplemento emigración).

MONTOLIU, Jaime (16 junio 1976): Avances del Movimiento Feminista. Profundizar en el debate. Mundo Obrero, ${ }^{\circ}$ 24, p. 7.

MONTOLIU, Jaime (7 julio 1976): Conferencia del Partido sobre la Mujer. Mundo Obrero, $\mathrm{n}^{\circ}$ 27, p. 12.

MORENO SARDÁ, Amparo (1977): Mujeres en lucha. El movimiento feminista en España. Barcelona: Anagrama.

MORENO SARDÁ, Amparo (1988): La replica de las mujeres al franquismo. En, Folguera, P., comp., El feminismo en España: Dos siglos de Historia, pp. 85-110. Madrid: Pablo Iglesias.

N. P. (20 de diciembre 1969): Más mujeres para el Partido. Mundo Obrero, p. 7.

OTERO, Gloria (22-28 mayo 1980): Más feministas, menos feminismo. Mundo Obrero, $n^{\circ} 76$, pp. 20-21.

P. P .F. y A. G. (3-9 abril 1981): Encuentros sobre feminismo y política. El fascismo agudiza el patriarcado. Mundo Obrero, ${ }^{0} 120$, p. 11.

Primeras Jornadas para la Liberación de la Mujer (diciembre 1975). Gaceta de Derecho Social, $\mathrm{n}^{\circ}$ 55, p. 31.

PUTXET, Clara (16 junio 1976): Avances del movimiento feminista. Jornades Catalanes de la Dona. Mundo Obrero, no 24, p. 6.

ROMEU ALFARO, Fernanda (1994): El Silencio roto. Mujeres contra el franquismo. ( $2^{\mathrm{a}}$ edición a cargo de la autora), 1994. 
SALAS, Mary y COMABELLA, Merche (1999): Asociaciones de Mujeres y movimiento feminista. En, Españolas en la Transición. De excluidas a protagonistas (1973-1982), pp. 25-125. Madrid: Biblioteca Nueva.

SAN JOSÉ, Begoña (marzo 1979): Día internacional de la mujer trabajadora. Gaceta de Derecho Social, ${ }^{\circ}$ 94, p. 15.

SAN JOSÉ, Begoña (1998): Democracia e Igualdad de derechos laborales de la mujer. Madrid: Instituto de la Mujer.

SÁNCHEZ LÓPEZ, Rosario (1990): Mujer española, una sombra de destino en lo universal. Trayectoria histórica de Sección Femenina de Falange (1934-1977). Murcia: Universidad de Murcia.

SARA (1 marzo 1973): La incorporación de la mujer a la lucha política. Mundo Obrero, $\mathrm{n}^{\circ}$ 5, p. s/n. (suplemento emigración).

SCANLON, Geraldine M. (1990): El movimiento feminista en España, 1900-1985: Logros y dificultades. En Astelarra, J., comp., Participación política de las Mujeres, pp. 83-100. Madrid: C.I.S.

SEMINARIO DE ESTUDIOS SOCIOLÓGICOS DE LA MUJER (1986): El Movimiento Feminista en España. De 1960 a 1980. En, Borreguero, C.; Catena, E.; Gándara, C. y Salas, M., dir., La mujer española: de la tradición a la modernidad. (1960-1980), pp. 29-40. Madrid: Tecnos.

SEGURA Miguel (2 ${ }^{\mathrm{a}}$ semana abril de 1975): Ellas necesitan de su lucha, sí, pero también de la ayuda de todos. Mundo Obrero, 9, p. s/n (suplemento emigración). 